\title{
Benefit of inserting a (Cu/Pt) intermixing dual barrier for the blocking temperature distribution of exchange biased $\mathrm{Co} /(\mathrm{Cu} / \mathrm{Pt}) / \mathrm{IrMn}$ stacks
}

\author{
K. Akmaldinov, ${ }^{1,2}$ S. Auffret, ${ }^{1}$ I. Joumard, ${ }^{1}$ B. Dieny, ${ }^{1}$ and V. Baltz ${ }^{1, a)}$ \\ ${ }^{1}$ SPINTEC, UMR 8191 CNRS/INAC-CEA/UJF-Grenoble 1/Grenoble-INP, F-38054 Cedex, France \\ ${ }^{2}$ CROCUS Technology, F-38025 Grenoble, France
}

(Received 11 June 2013; accepted 12 July 2013; published online 25 July 2013)

\begin{abstract}
Exchange bias based spintronics devices involve ferromagnetic/antiferromagnetic interfaces and concomitant layers intermixing. As a consequence, interfacial spin-glass-like phases with reduced properties and increased dispersions form and lower the device performance. It is therefore necessary to limit intermixing by introduction of diffusion barriers. One of the major difficulties is that the barrier must be inert. This paper uses blocking temperature distributions to quantify the interfacial quality of $\mathrm{Co} / \mathrm{IrMn}$ based stacks. Inserting a $(\mathrm{Cu} / \mathrm{Pt})$ dual barrier fulfils the manifold requirements of limiting $\mathrm{Co}-\mathrm{Mn}, \mathrm{Co}-\mathrm{Pt}$, and $\mathrm{Cu}-\mathrm{Mn}$ intermixing, which takes place when using either no or single $\mathrm{Pt}$ and Cu barriers, respectively. (C) 2013 AIP Publishing LLC. [http://dx.doi.org/10.1063/1.4816816]
\end{abstract}

Spintronics applications ${ }^{1}$ use ferromagnetic (F)/antiferromagnetic (AF) exchange bias (EB) interactions ${ }^{2,3}$ to set the reference direction required for the spin of conduction electrons. They therefore may involve layers intermixing originating from F/AF interfaces. ${ }^{4-7}$ As a consequence of intermixing, interfacial spin-glass-like phases with reduced EB properties and increased dispersions form and may lower the devices performances. ${ }^{8-17}$ It is thereby necessary to limit intermixing. Diffusion barriers have been commonly implemented in the field of electronics. ${ }^{18-20}$ Although the science of diffusion barriers involves many aspects which often lead to compromise, ${ }^{18}$ one of the major difficulties is that the barrier must not corrupt the surrounding materials that it is supposed to be protecting. Some barriers may consist of multiple layers to accommodate such a need for non-reactivity. ${ }^{19,20}$ Here, we implement diffusion barrier and, in particular, dual barriers for the F/AF building block of spintronics devices. In particular, we focus on $\mathrm{F} / \mathrm{AF}$ cobalt/iridium-manganese $(\mathrm{Co} / \mathrm{IrMn})$ based stacks. This paper uses blocking temperature distributions $\left(\mathrm{DT}_{\mathrm{B}}\right)^{12,21}$ to quantify the interfacial quality of the F/AF interface, where $T_{B}$ is the temperature $(T)$ over which the $A F$ is no longer thermally stable when cycling the $\mathrm{F}$ magnetization. ${ }^{2,3}$ In fact, it is now accepted that EB is ascribed to the ability of both $\mathrm{AF}$ grains (domains) and $\mathrm{AF}$ interfacial spin-glass-like phases to withstand $\mathrm{F}$ magnetization reversal. ${ }^{8-17,21,22}$ The specific procedure commonly carried out for measurements of $\mathrm{DT}_{\mathrm{B}}$ above $300 \mathrm{~K}$ (Ref. 21) combined with the alternative use of a sufficiently low reference- $\mathrm{T}$ recently provided a method for probing the low-T contribution to $\mathrm{DT}_{\mathrm{B}}$ related to interfacial spin-glass. ${ }^{12}$ We expect that inserting a copper/platinum $(\mathrm{Cu} / \mathrm{Pt})$ dual barrier between $\mathrm{Co}$ and IrMn will fulfil the manifold requirements of limiting the various species intermixing which takes place when using either no or single barriers ${ }^{4-7,11,17,23-25}$ and that this will translate into less glassy interfaces, i.e., into the observation of lower $\mathrm{T}_{\mathrm{B}}$ dispersions.

In this study, Ta $(3 \mathrm{~nm}) / \mathrm{Cu}(3 \mathrm{~nm}) / \mathrm{Co}(3 \mathrm{~nm}) / \mathrm{Cu}\left(\mathrm{t}_{\mathrm{Cu}}\right) / \mathrm{Pt}$ $\left(\mathrm{t}_{\mathrm{Pt}}\right) / \mathrm{IrMn}(7 \mathrm{~nm}) / \mathrm{Pt}(2 \mathrm{~nm})$ and $\mathrm{Ta}(3 \mathrm{~nm}) / \mathrm{Cu}(3 \mathrm{~nm}) / \mathrm{IrMn}$ $(7 \mathrm{~nm}) / \mathrm{Pt}\left(\mathrm{t}_{\mathrm{Pt}}\right) / \mathrm{Cu}\left(\mathrm{t}_{\mathrm{Cu}}\right) / \mathrm{Co}(3 \mathrm{~nm}) / \mathrm{Pt}(2 \mathrm{~nm})$ are deposited at

\footnotetext{
a) Author to whom correspondence should be addressed. Electronic mail: vincent.baltz@cea.fr
}

room- $\mathrm{T}$ by magnetron sputtering onto thermally oxidised silicon substrates, $\mathrm{Si} / \mathrm{SiO}_{2}{ }^{12}$ The $\mathrm{Ta}(3 \mathrm{~nm}) / \mathrm{Cu}(3 \mathrm{~nm})$ bilayer is used as buffer, and the $\mathrm{Pt}(2 \mathrm{~nm})$ film is the capping layer. Co $(3 \mathrm{~nm})$ is the ferromagnet, and $\operatorname{IrMn}(7 \mathrm{~nm})$ is the antiferromagnet made from an $\mathrm{Ir}_{20} \mathrm{Mn}_{80}$ target. The $\mathrm{Cu}$ and Pt thicknesses of the $(\mathrm{Cu} / \mathrm{Pt})$ and $(\mathrm{Pt} / \mathrm{Cu})$ intermixing dual barriers are $\mathrm{t}_{\mathrm{Cu}}$ and $\mathrm{t}_{\mathrm{Pt}}$, respectively, and take values between 0 and $6 \mathrm{~nm}$. Thick barriers are used here in order to study complete films. Room-T EB is set by post-deposition field cooling (FC) of the samples for $1 \mathrm{~h}$ in a furnace from $573 \mathrm{~K}$ down to room-T. The positive magnetic field during cooling is applied in the samples planes, and its amplitude of $2.5 \mathrm{kOe}$ is large enough to saturate the Co layers. Following this initial FC, all the AF entities with $\mathrm{T}_{\mathrm{B}}$ larger than room- $\mathrm{T}$ are oriented toward the positive direction. ${ }^{12}$ Room-T hysteresis loops are then measured. Subsequent initial positive FC is continued from 400 to $4 \mathrm{~K}$ in the variable $\mathrm{T}$ insert of a vibrating sample magnetometer $(\mathrm{VSM}) . \mathrm{DT}_{\mathrm{B}}$ in the range of $4-400 \mathrm{~K}$ are then deduced from hysteresis loops measured at $4 \mathrm{~K}$ with the VSM after a specific procedure which includes FC from incremental annealing temperatures $\left(\mathrm{T}_{\mathrm{a}}\right)$. The procedure and typical hysteresis loops are thoroughly detailed elsewhere. ${ }^{12,21}$ In brief, after initial positive $\mathrm{FC}$ from 573 to $4 \mathrm{~K}$, all the AF entities contributing to EB orient positively. The resulting hysteresis loop shift $\left(\mathrm{H}_{\mathrm{E}}\right)$ is negative and maximum in amplitude (see $\mathrm{T}_{\mathrm{a}}=4 \mathrm{~K}$ in Fig. 1). From this initial state the AF entities are progressively reoriented by use of negative FC down to $4 \mathrm{~K}$ from incremental $T_{a}$. The AF entities with $T_{B}$ lower than $T_{a}$ reverse. A hysteresis loop is measured at $4 \mathrm{~K}$ after each increment. Its shift in field is proportional to the difference between pinned AF entities oriented positively and negatively. A gradual change in the amplitude and sign of $\mathrm{H}_{\mathrm{E}}$ is observed (see Fig. 1) since the higher the $T_{a}$ the more the reversed entities. At each increment of $\mathrm{T}_{\mathrm{a}}, \mathrm{H}_{\mathrm{E}}$ reflects the difference between AF entities with $T_{B}$ larger and lower than $T_{a}$. It follows by definition that the variations of the derivative $\delta \mathrm{H}_{\mathrm{E}} / \delta \mathrm{T}_{\mathrm{a}}$ with $\mathrm{T}_{\mathrm{a}}$ represent $\mathrm{DT}_{\mathrm{B}}$. Thus (i) an inflection point for $\mathrm{H}_{\mathrm{E}}$ vs $\mathrm{T}_{\mathrm{a}}$ denotes a peak in the distribution, and (ii) the amplitude of $\mathrm{H}_{\mathrm{E}}$ $\left(\Delta \mathrm{H}_{\mathrm{E}}\right)$ around the inflection is the surface of the peak. In the following, $\Delta \mathrm{H}_{\mathrm{E}}$ is the difference between $\mathrm{H}_{\mathrm{E}}$ after $\mathrm{Ta}=4$ and $200 \mathrm{~K}$ (i.e., after the inflection, on the plateau). 


\section{(a)}

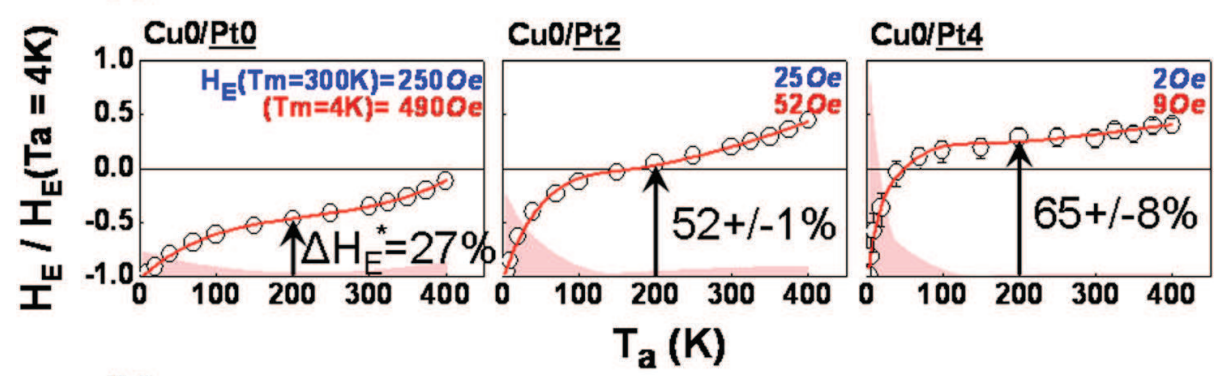

(b)

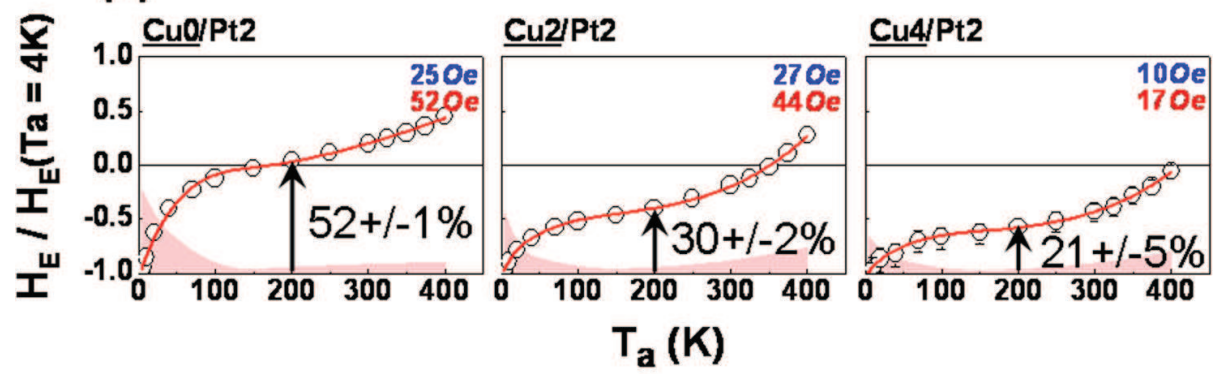

\section{(c)}

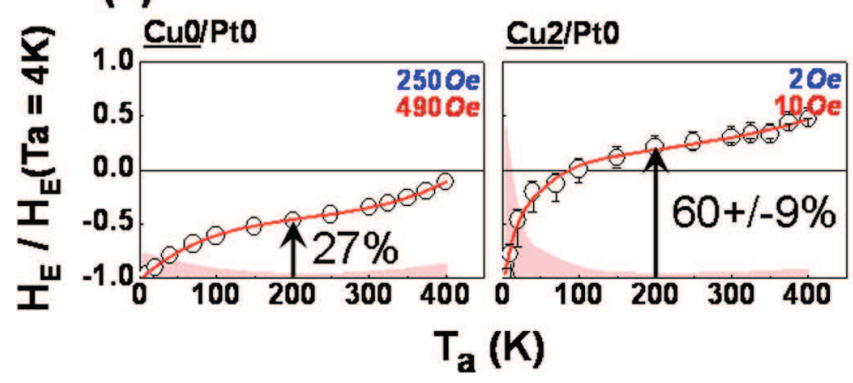

FIG. 1. Front: variations with the annealing temperatures $\left(\mathrm{T}_{\mathrm{a}}\right)$ of the normalized loop shift $\left(\mathrm{H}_{\mathrm{E}} / \mathrm{H}_{\mathrm{E}}\left(\mathrm{T}_{\mathrm{a}}=4 \mathrm{~K}\right) \mathrm{l}\right)$ deduced from hysteresis loops measured at $4 \mathrm{~K}$ by VSM along the field cooling (FC) direction for samples with composition: $\mathrm{Si} / \mathrm{SiO}_{2} / / \mathrm{Ta}(3 \mathrm{~nm}) /$ $\mathrm{Cu}(3 \mathrm{~nm}) / \mathrm{Co}(3 \mathrm{~nm}) / \mathrm{Cu}\left(\mathrm{t}_{\mathrm{Cu}}\right) / \mathrm{Pt}\left(\mathrm{t}_{\mathrm{Pt}}\right) /$ $\operatorname{IrMn}(7 \mathrm{~nm}) / \mathrm{Pt}(2 \mathrm{~nm})$ and subject to a procedure detailed within the text and involving various $\mathrm{T}_{\mathrm{a}}$. The $\mathrm{Cu}$ and $\mathrm{Pt}$ thicknesses of the $\mathrm{Cu} / \mathrm{Pt}$ intermixing dual barrier are $t_{C u}$ and $t_{P t}$, respectively: (a) $\mathrm{t}_{\mathrm{Cu}}=0$ and varying $\mathrm{t}_{\mathrm{Pt}}$; (b) $t_{P t}=2 \mathrm{~nm}$ and varying $t_{C u}$; and (c) $t_{P t}=0$ and varying $t_{C u}$. To ease the reading, the plots in Fig. 1(a) for $\mathrm{CuO} /$ $\mathrm{Pt} 0$ and $\mathrm{Cu} 0 / \mathrm{Pt} 2$ are reproduced in Figs. 1(b) and 1(c), respectively. The full lines in the graphs result from interpolation of the data. Back: variations with $\mathrm{T}_{\mathrm{a}}$ of the normalized derivatives $\delta \mathrm{H}_{\mathrm{E}} / \delta \mathrm{T}_{\mathrm{a}}$ deduced from the full lines. $\delta \mathrm{H}_{\mathrm{E}} / \delta \mathrm{T}_{\mathrm{a}}$ vs $\mathrm{T}_{\mathrm{a}}$ represent the blocking temperature distributions. The absolute values of $\mathrm{H}_{\mathrm{E}}$ measured at $\mathrm{T}_{\mathrm{m}}=300$ and $4 \mathrm{~K}$ after positive $\mathrm{FC}$ from $573 \mathrm{~K}$ to $\mathrm{T}_{\mathrm{m}}$ are indicated.
Figure 1 shows the variations with $\mathrm{T}_{\mathrm{a}}$ of the normalized loop shifts, $\mathrm{H}_{\mathrm{E}} /\left|\mathrm{H}_{\mathrm{E}}\left(\mathrm{T}_{\mathrm{a}}=4 \mathrm{~K}\right)\right|$ (front) and the corresponding $\mathrm{DT}_{\mathrm{B}}$ (back) for $\mathrm{Si} / \mathrm{SiO}_{2} / / \mathrm{Ta}(3 \mathrm{~nm}) / \mathrm{Cu}(3 \mathrm{~nm}) / \mathrm{Co}(3 \mathrm{~nm}) / \mathrm{Cu}$ $\left(\mathrm{t}_{\mathrm{Cu}}\right) / \mathrm{Pt}\left(\mathrm{t}_{\mathrm{Pt}}\right) / \mathrm{IrMn}(7 \mathrm{~nm}) / \mathrm{Pt}(2 \mathrm{~nm})$ with various intermixing barriers. For all the samples, the low-T contribution to $\mathrm{DT}_{\mathrm{B}}$ known to originate from $\mathrm{AF}$ interfacial spin-glass-like phases $^{9-13}$ is fully observed. Given that $\Delta \mathrm{H}_{\mathrm{E}}$ also denotes the glassy character of the surface. This is represented by $\Delta \mathrm{H}_{\mathrm{E}}{ }^{*}$ and arrows in Figs. 1 and 2 and expressed in percentage: $\Delta \mathrm{H}_{\mathrm{E}} *$ equals $\Delta \mathrm{H}_{\mathrm{E}}$ normalized to the total expected variations of $\mathrm{H}_{\mathrm{E}}$, i.e., 2 for normalized $\mathrm{H}_{\mathrm{E}}$ : from -1 to 1 . The beginning of the second inflection point in the $H_{E}$ vs $T_{a}$ variations witnesses the high- $T$ contribution to $\mathrm{DT}_{\mathrm{B}}$ related to the grains sizes dispersion. $^{9-13}$ This contribution exists for all the samples since $\mathrm{H}_{\mathrm{E}}$ is due to reach back its maximum amplitude but with opposite sign for larger $\mathrm{T}_{\mathrm{a}}$, i.e., when all the AF entities are reoriented. ${ }^{12}$

It is known that Co-Mn intermixing exists at $\mathrm{Co} / \mathrm{IrMn}$ interfaces, ${ }^{4,6,7}$ and it has been observed that a Pt insertion limits such intermixing, ${ }^{6,7}$ which should be beneficial for the interfacial quality. However, Pt is not an inert barrier here since it is fully miscible with Co. As a result, CoPt alloys with reduced ordering $\mathrm{T}$ around the Co-Pt interface form. ${ }^{4,6,7,14} \mathrm{As}$ a consequence, Fig. 1(a) shows that compared to no Pt inclusion, $\Delta \mathrm{H}_{\mathrm{E}} *$ and thus $\mathrm{DT}_{\mathrm{B}}$ increases when a $2 \mathrm{~nm}$ thick $\mathrm{Pt}$ is inserted (from $\sim 27$ to $\sim 52 \%$ ). This confirms that the interfacial quality actually worsened. Figure 1(a) also shows that the thicker the $\mathrm{Pt}(0 ; 2$, and $4 \mathrm{~nm})$, the larger the $\Delta \mathrm{H}_{\mathrm{E}} *$ and thus the larger the $\mathrm{DT}_{\mathrm{B}}$ contribution $(\sim 21 ; \sim 52$ and $\sim 65 \%$, respectively). This implies that the thicker the Pt insertion, the more glassy the interface. It may mean that the Co or Pt diffusion lengths in our experimental conditions are larger than $t_{\mathrm{Pt}}$ or $\mathrm{t}_{\mathrm{Co}}$. Pt and Co diffusions through grain boundaries are also not excluded. ${ }^{6,18}$ To avoid Co-Pt intermixing in the case of a single $\mathrm{Pt}$ barrier we further added a $\mathrm{Cu}$ layer, immiscible with Co (Refs. 4 and 26) and obtained a dual $(\mathrm{Cu} / \mathrm{Pt})$ barrier. By looking at the plots for $(\mathrm{Cu} 0 / \mathrm{Pt} 2)$ and $(\mathrm{Cu} 2 / \mathrm{P} 2)$, Fig. 1(b) shows that this further $\mathrm{Cu}$ insertion indeed reduces $\mathrm{DT}_{\mathrm{B}}$ (from $\sim 52$ to $\sim 30 \%$ ) and therefore increases the interfacial quality. Additionally, Fig. 1(b) shows that for $(\mathrm{Cu} / \mathrm{Pt} 2)$ dual barriers, the thicker the $\mathrm{Cu}(0 ; 2$ and $4 \mathrm{~nm})$, the smaller the $\mathrm{DT}_{\mathrm{B}}(\sim 52$; $\sim 30$ and $\sim 21 \%$, respectively). For similar reasons as above, diffusion length vs film thickness or $\mathrm{Co}$ and $\mathrm{Pt}$ diffusions via grain boundaries may be argued. It is noticeable that $\mathrm{DT}_{\mathrm{B}}$ for a Co/(Cu4/Pt2)/IrMn stack [ 21\%, see third plot in Fig. 1(b)], i.e., with an intermixing dual barrier, is smaller than $\mathrm{DT}_{\mathrm{B}}$ for a $\mathrm{Co} / \mathrm{IrMn}$ bilayer [ 27\%, see first plot in Fig. 1(b)], i.e., without any intermixing barrier. This thus proves that an efficient inert intermixing barrier is a viable solution to limit the dispersions of $T_{B}$ in exchange biased stacks, but, as a counterpart, it weakens $\mathrm{H}_{\mathrm{E}}$ by taking the $\mathrm{F}$ away from the $\mathrm{AF}$ (see values in Fig. 1). ${ }^{25}$ However, in Fig. 1(b), when comparing $(\mathrm{Cu} 0 / \mathrm{Pt} 2)$ and $(\mathrm{Cu} 2 / \mathrm{P} 2)$ we remark that the relative changes of $\mathrm{H}_{\mathrm{E}}$ are very limited (from 52 to $44 \mathrm{Oe}$ for a measurement $\mathrm{T}$ of $4 \mathrm{~K}$ ) 
(a)

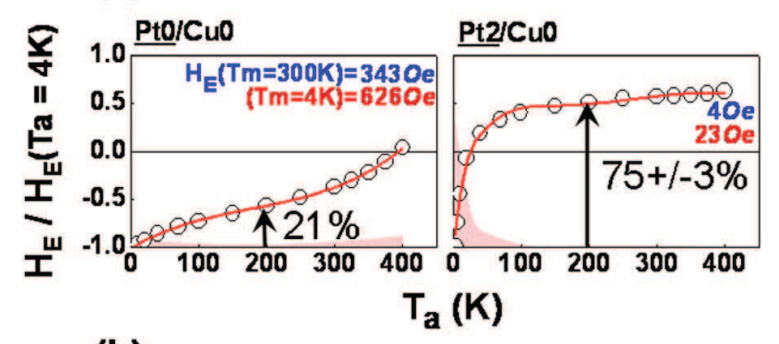

(b)
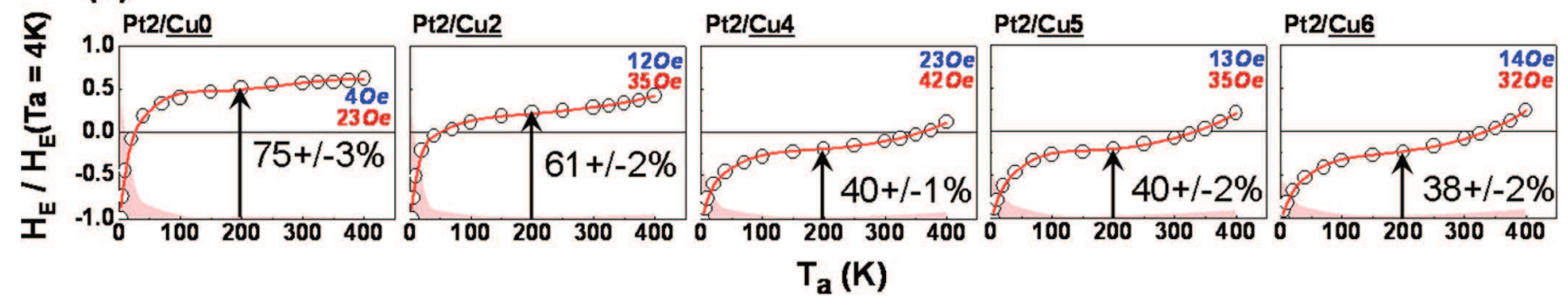

(c)

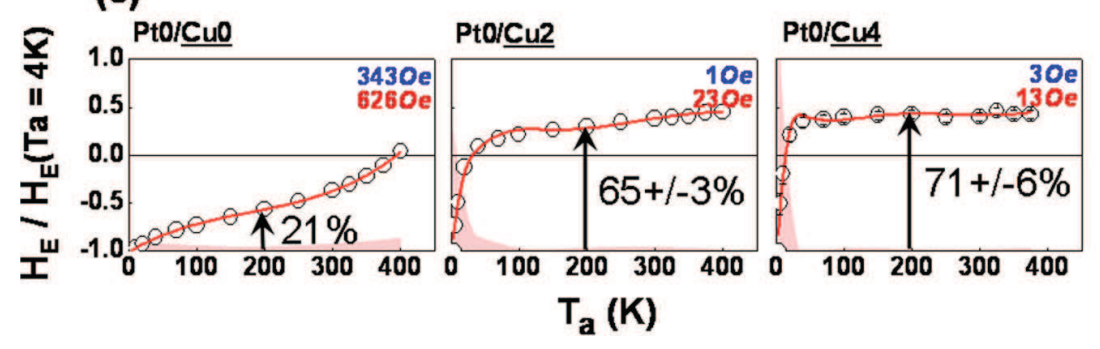

FIG. 2. Front: variations with $\mathrm{T}_{\mathrm{a}}$ of $\mathrm{H}_{\mathrm{E}} / \mathrm{H}_{\mathrm{E}}\left(\mathrm{T}_{\mathrm{a}}=4 \mathrm{~K}\right) \mid$ for the inverted structures: $\mathrm{Si} / \mathrm{SiO}_{2} / / \mathrm{Ta}(3 \mathrm{~nm}) / \mathrm{Cu}(3 \mathrm{~nm}) / \mathrm{IrMn}(7 \mathrm{~nm}) / \mathrm{Pt}\left(\mathrm{t}_{\mathrm{Pt}}\right) / \mathrm{Cu}\left(\mathrm{t}_{\mathrm{Cu}}\right) / \mathrm{Co}(3 \mathrm{~nm}) / \mathrm{Pt}$ $\left(2 \mathrm{~nm}\right.$ ) with: (a) $\mathrm{t}_{\mathrm{Cu}}=0$ and varying $\mathrm{t}_{\mathrm{Pt}}$; (b) $\mathrm{t}_{\mathrm{Pt}}=2 \mathrm{~nm}$ and varying $\mathrm{t}_{\mathrm{Cu}}$; and (c) $\mathrm{t}_{\mathrm{Pt}}=0$ and varying $\mathrm{t}_{\mathrm{Cu}}$. The full lines in the graphs result from interpolation of the data. Back: variations with $\mathrm{T}_{\mathrm{a}}$ of the normalized derivatives $\delta \mathrm{H}_{\mathrm{E}} / \delta \mathrm{T}_{\mathrm{a}}$ deduced from the full lines. The absolute values of $\mathrm{H}_{\mathrm{E}}$ measured at $\mathrm{T}_{\mathrm{m}}=300$ and $4 \mathrm{~K}$ after positive $\mathrm{FC}$ from $573 \mathrm{~K}$ to $\mathrm{T}_{\mathrm{m}}$ are indicated.

despite the addition of as much as $2 \mathrm{~nm}$ more between the $\mathrm{F}$ and the AF. This result is encouraging and introduces the fact that the benefits of intermixing limitations may, in some conditions, overcome the disadvantages of spacing augment between the $\mathrm{F}$ and the AF. Finally, notice that the sole insertion of a single $\mathrm{Cu}$ barrier as opposed to a dual $(\mathrm{Cu} / \mathrm{Pt})$ barrier leads to larger $\mathrm{DT}_{\mathrm{B}}$; thus, to more glassy interfaces, as concluded from Fig. 1(c), the case $(\mathrm{Cu} 4 / \mathrm{Pt} 0)$ virtually gave zero loop shift, and no $\mathrm{DT}_{\mathrm{B}}$ could be measured. We argue that $\mathrm{Cu}$ and $\mathrm{Mn}$ are indeed miscible and that $\mathrm{CuMn}$ alloys are known to lead to spin-glass phases. ${ }^{11,17,23,24}$

In order to strengthen our findings and confirm that the effect is predominantly driven by layers intermixing and not by potential structural or roughness changes, we systematically performed measurements for the reversed structures. Figure 2 shows the results for $\mathrm{Si} / \mathrm{SiO}_{2} / / \mathrm{Ta}(3 \mathrm{~nm}) / \mathrm{Cu}(3 \mathrm{~nm}) /$ IrMn $(7 \mathrm{~nm}) / \mathrm{Pt}\left(\mathrm{t}_{\mathrm{Pt}}\right) / \mathrm{Cu}\left(\mathrm{t}_{\mathrm{Cu}}\right) / \mathrm{Co}(3 \mathrm{~nm}) / \mathrm{Pt}(2 \mathrm{~nm})$. We note that the top and bottom IrMn stacks are certainly not symmetrical due to growth issues on various buffers which influences interface roughness, alloying, layers structures, etc. and affect the $\mathrm{H}_{\mathrm{E}}$ absolute values differences between top and bottom stacks. ${ }^{26,27}$ For example, although $(\mathrm{Cu} 0 / \mathrm{Pt} 4)$ and $(\mathrm{Pt} 0 / \mathrm{Cu} 4)$ based samples gave a non-zero $\mathrm{H}_{\mathrm{E}}$, thus allowing $\mathrm{DT}_{\mathrm{B}}$ measurements, the cases $(\mathrm{Cu} 4 / \mathrm{Pt} 0)$ and $(\mathrm{Pt} 4 / \mathrm{Cu} 0)$ gave zero $\mathrm{H}_{\mathrm{E}}$, and thus no $\mathrm{DT}_{\mathrm{B}}$ could be measured. The origins of the differences between top and bottom IrMn structures were already studied in the literature and are out of the scope of the present paper. Although the absolute values of $\mathrm{H}_{\mathrm{E}}$ and $\Delta \mathrm{H}_{\mathrm{E}} *$ vary between top and bottom IrMn, in agreement with previous results, ${ }^{27}$ similar trends were obtained after the addition of the barriers, thus leading to analogous conclusions. This indeed confirms that our relative observations are predominantly related to intermixing. The barriers addition certainly has other consequences, e.g., on roughness, which surely depend on the top or bottom character of the stack, but such other consequences mainly influence the absolute values differences between top and bottom and not the relative trends for a given top or bottom stack. In brief, Fig. 2(a) shows the effect of PtCo intermixing when adding a single Pt barrier to limit MnCo intermixing, which leads to more glassy interfaces and thus to larger $\mathrm{DT}_{\mathrm{B}}\left(\sim 21\right.$ and $\sim 75 \%$ for $\mathrm{t}_{\mathrm{Pt}}=0$ and $2 \mathrm{~nm}$, respectively). Figure 2(c) shows the effect of $\mathrm{Cu}-\mathrm{Mn}$ intermixing when adding a single $\mathrm{Cu}$ barrier, which also leads to larger DT $_{\mathrm{B}}\left(\sim 21 ; \sim 65\right.$ and $\sim 71 \%$ for $\mathrm{t}_{\mathrm{Cu}}=0 ; 2$ and $4 \mathrm{~nm}$, respectively). Finally, Fig. 2(b) confirms the beneficial effect of (Pt/ $\mathrm{Cu})$ dual barriers for the reductions of $\mathrm{DT}_{\mathrm{B}}$. The corresponding values of $\mathrm{H}_{\mathrm{E}}$ and $\Delta \mathrm{H}_{\mathrm{E}}{ }^{*}$ are plotted together in Fig. 3(a). When the $\mathrm{Cu}$ thickness of the $(\mathrm{Pt} 2 / \mathrm{Cu})$ tandem increases, the interfacial quality improves up to a threshold value $\left(t_{\mathrm{Cu}}=4 \mathrm{~nm}\right)$ and levels out above. For our sputtering deposition process (which certainly participate to the activation of some lattice defects within grains ${ }^{6,7}$ ) and post-deposition annealing (at $573 \mathrm{~K}$ for $1 \mathrm{~h}$ ), diffusion may occur via the core of each grain and via grain boundaries. ${ }^{18}$ This may happen up 
(a)

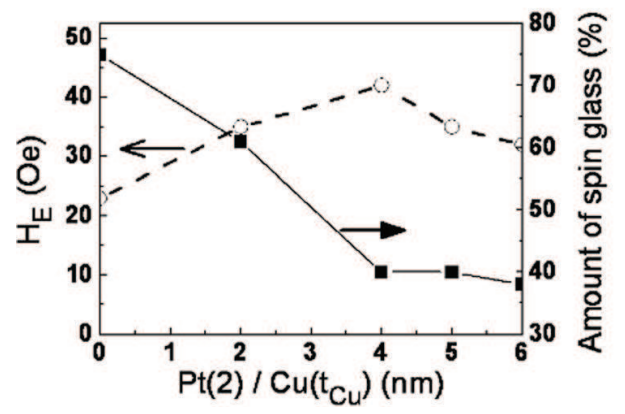

(b)

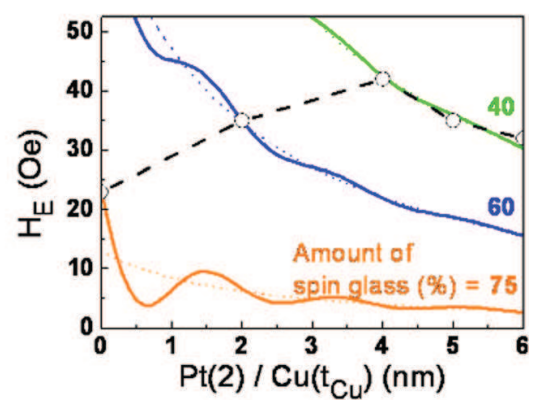

FIG. 3. (a) Variations of the hysteresis loop shift $\left(\mathrm{H}_{\mathrm{E}}\right)$ measured at $4 \mathrm{~K}$ and of the relative amount of spin glass deduced from Fig. 2(b) as a function of the $\mathrm{Cu}$ thickness $\left(\mathrm{t}_{\mathrm{Cu}}\right)$ for samples of $\mathrm{Si} / \mathrm{SiO}_{2} / / \mathrm{Ta}(3 \mathrm{~nm}) / \mathrm{Cu}(3 \mathrm{~nm}) / \mathrm{IrMn}$ $(7 \mathrm{~nm}) / \mathrm{Pt}(2 \mathrm{~nm}) / \mathrm{Cu}\left(\mathrm{t}_{\mathrm{Cu}}\right) / \mathrm{Co}(3 \mathrm{~nm}) / \mathrm{Pt}$ $(2 \mathrm{~nm})$. (b) Comparison of the experimental $\mathrm{H}_{\mathrm{E}} \mathrm{vs}_{\mathrm{Cu}}$ plot reproduced from Fig. 3(a) (data points and dashed line) with series of expected $\mathrm{H}_{\mathrm{E}}$ vs $\mathrm{t}_{\mathrm{Cu}}$ trends for various relative amount of spin glass, i.e., for various interfacial qualities (dotted full lines in color). to a threshold thickness larger than the diffusion lengths in the grains and grain boundaries. Actually, it is known that, in some conditions, grain boundaries and defects offer paths with enhance atomic mobility, thereby possibly dominating the atomic transport. ${ }^{18}$ We also note that our $(\mathrm{Pt} / \mathrm{Cu})$ dual barrier is surely a more complex barrier since $\mathrm{Pt}$ and $\mathrm{Cu}$ do mix. ${ }^{4}$ Attempts with $(\mathrm{Ru} 2 / \mathrm{Cu} 2)$ barriers in which $\mathrm{Ru}$ and $\mathrm{Cu}$ are not miscible ${ }^{4}$ did not show any $\mathrm{H}_{\mathrm{E}}$ probably due to $\mathrm{Ru}$ and $\mathrm{Mn}$ intermixing and to wetting issues of $\mathrm{Cu}$ on $\mathrm{Ru}$. This, thus, points out the importance of the choice of the materials in the dual barrier even if these latter are miscible between them and provided that they are efficient barriers for the surrounding materials. From Fig. 3(a), we also observe that $\mathrm{H}_{\mathrm{E}}$ first increases when the amount of spin-glass decreases (i.e., when the interfacial quality improves) and then reduces when the amount of spin-glass levels out. Figure 3(b) helps us to explain this behaviour. First note that the exchange interactions between Co and IrMn through $2 \mathrm{~nm}$ of Pt plus 2 to $6 \mathrm{~nm}$ of $\mathrm{Cu}$ (or more likely through a $\mathrm{PtCu}$ alloy) are surely mediated by itinerant $s$ electrons. ${ }^{28,29}$ To a first approximation this sounds plausible, since the spin diffusion lengths in $\mathrm{Pt}, \mathrm{Cu}$, and some $\mathrm{PtCu}$ alloys can be larger, at $4 \mathrm{~K}$, than the above mentioned characteristic lengths. ${ }^{30}$ In particular, an oscillating behaviour of the magnetic properties for [PtCu-alloys/Co] multilayers $^{28}$ was already reported in the literature. Additionally, long range interactions have been modelled and experimentally reported in the literature between a $\mathrm{F}$ and an $\mathrm{AF}$, although the spacer did not involve Pt nor a Pt based alloys. ${ }^{31-35}$ Finally, we attempted (Pt1/AlOx2/Cu1) trilayer barrier. The total barrier thickness was set to $4 \mathrm{~nm}$ so as to compare with the $(\mathrm{Pt} 2 / \mathrm{Cu} 2)$ dual barrier. No loop shift was obtained (hence no distribution could be measured). Since our $\mathrm{AlOx}$ is insulating it may break the IrMn-Co long range interaction. This result probably supports the idea of long range mediation via itinerant $s$ electrons. In Fig. 3(b), we plotted a series of oscillatory decreasing loops of the form: $\mathrm{A} \times \exp$ $(-\mathrm{t} / \mathrm{L}) / \mathrm{t}+\mathrm{B} \times(\mathrm{C} \times \mathrm{t} \times \cos (\mathrm{C} \times \mathrm{t})-\sin (\mathrm{C} \times \mathrm{t})) /(\mathrm{C} \times \mathrm{t}){ }^{4}{ }^{4}$ The first term represents the reduction of $\mathrm{H}_{\mathrm{E}}$ ascribed to spacing augment between the $\mathrm{F}$ and the $\mathrm{AF}^{25}$ and the second term models additional RKKY long range interactions. ${ }^{28}$ These curves are guides to the eye, and A, B, C, and L have been assigned arbitrary values. B, C, and L were kept constant, while A was increased to model an interfacial improvement. The variable $t$ is the total thickness of the dual barrier. This series of virtual master curves reads as follows: the interface gradually improves when switching from the orange curve (75\%) to the dark blue $(60 \%)$ and to the green curve $(40 \%)$.
The interfacial improvement experimentally measured between 0 and $4 \mathrm{~nm}$ of $\mathrm{Cu}$ [see Fig. 3(a)] means that the corresponding virtual $\mathrm{H}_{\mathrm{E}}$ should jump from master curve to master curve. As shown in Fig. 3(b) this is in agreement with the experimental increase of $\mathrm{H}_{\mathrm{E}}$. When the interfacial quality levels out, above $\mathrm{t}_{\mathrm{Cu}}=4 \mathrm{~nm}$ as experimentally observed in Fig. 3(a), the related virtual $\mathrm{H}_{\mathrm{E}}$ should stick to the same curve: here, the green curve $(40 \%)$ in Fig. 3(b). It then follows the decrease due to the gradual separation of the $\mathrm{F}$ and the $\mathrm{AF}$, which is also in agreement with the experimental trend. Although adding a diffusion barrier to bare $\mathrm{Co} / \mathrm{IrMn}$ did not fulfil at once interfacial improvement (i.e., spin-glass reductions) and preservation of a decent value for $\mathrm{H}_{\mathrm{E}}$, for the $(\mathrm{Pt} 2 / \mathrm{Cu})$ series [Fig. 3(a)] we evidenced that, in some conditions and despite the F-AF spacing augment, it was possible, via the addition of diffusion barriers, to simultaneously increase $\mathrm{H}_{\mathrm{E}}$ and lower the $\mathrm{T}_{\mathrm{B}}$ dispersions.

To conclude, the report of layers intermixing at ferromagnetic/antiferromagnetic exchange biased interfaces and concomitant formation of interfacial spin-glass-like phases with reduced properties and increased dispersions led us to engineer diffusion barriers. $\mathrm{Cu}$ and $\mathrm{Pt}$ based barriers were inserted at $\mathrm{Co} / \mathrm{IrMn}$ interfaces, and the interfacial quality potential improvement was investigated via measurements of the lowtemperature contributions to the blocking temperature distributions: the smaller the contribution, the less glassy the interface. The use of $(\mathrm{Cu} / \mathrm{Pt})$ intermixing dual barriers led to blocking temperature distributions reductions as a result of interfaces improvements. All at once, $(\mathrm{Cu} / \mathrm{Pt})$ limited $\mathrm{Co}-\mathrm{Mn}$, $\mathrm{Co}-\mathrm{Pt}$, and $\mathrm{Cu}-\mathrm{Mn}$ mixing, which took place when using either no or single $\mathrm{Pt}$ and $\mathrm{Cu}$ barriers. Although inserting $(\mathrm{Cu} /$ $\mathrm{Pt}$ ) intermixing dual barriers was beneficial for the exchange bias properties dispersions, it weakened the loop shift amplitudes by taking the ferromagnet away from the antiferromagnet. However, some encouraging data suggested that it is in principle possible to find barriers for which the benefits of intermixing limitations overcome the disadvantages of spacing augment between the ferromagnet and the antiferromagnet. Since $\mathrm{Cu}$ and $\mathrm{Pt}$ are miscible, complementary studies with $\mathrm{Cu}_{\mathrm{x}} \mathrm{Pt}_{1-\mathrm{x}}$ barriers would be interesting, although polycrystalline $\mathrm{Cu}_{\mathrm{x}} \mathrm{Pt}_{1-\mathrm{x}}$ alloys may also diffuse throughout grain boundaries. Other complementary studies could involve amorphous layers in order to avoid diffusion via grain boundaries.

This work was partially funded by the European Commission via the ERC advanced grant HYMAGINE (No. 246942). 
${ }^{1}$ S. A. Wolf, D. D. Awschalom, R. A. Buhrman, J. M. Daughton, S. von Molna, M. L. Roukes, A. Y. Chtchelkanova, and D. M. Treger, Science 294, 1488 (2001).

${ }^{2}$ J. Nogués and I. K. Schuller, J. Magn. Magn. Mater. 192, 203 (1999).

${ }^{3}$ A. E. Berkowitz and K. Takano, J. Magn. Magn. Mater. 200, 552 (1999).

${ }^{4}$ R. M. Bozorth, Ferromagnetism (D. Van Nostrand Company, Inc., 1951).

${ }^{5}$ X. W. Zhou, H. N. G. Wadley, R. A. Johnson, D. J. Larson, N. Tabat, A.

Cerezo, A. K. Petford-Long, G. D. W. Smith, P. H. Clifton, R. L. Martens, and T. F. Kelly, Acta Mater. 49, 4005 (2001).

${ }^{6}$ L. Lechevallier, A. Zarefy, F. Letellier, R. Lardé, D. Blavette, J. M. Le Breton, V. Baltz, B. Rodmacq, and B. Dieny, J. Appl. Phys. 112, 043904 (2012).

${ }^{7}$ F. Letellier, V. Baltz, L. Lechevallier, R. Lardé, J.-F. Jacquot, B. Rodmacq, J.-M. Le Breton, and B. Dieny, J. Phys. D: Appl. Phys. 45, 275001 (2012).

${ }^{8}$ A. P. Malozemoff, Phys. Rev. B 35, 3679 (1987).

${ }^{9}$ K. Takano, R. H. Kodama, A. E. Berkowitz, W. Cao, and G. Thomas, Phys. Rev. Lett. 79, 1130 (1997).

${ }^{10}$ J. Ventura, J. P. Araujo, J. B. Sousa, A. Veloso, and P. P. Freitas, J. Appl. Phys. 101, 113901 (2007).

${ }^{11}$ M. Ali, P. Adie, C. H. Marrows, D. Greig, B. J. Hickey, and R. L. Stamps, Nat. Mater. 6, 70 (2007).

${ }^{12}$ V. Baltz, B. Rodmacq, A. Zarefy, L. Lechevallier, and B. Dieny, Phys. Rev. B 81, 052404 (2010).

${ }^{13}$ K. O'Grady, L. E. Fernandez-Outon, and G. Vallejo-Fernandez, J. Magn. Magn. Mater. 322, 883 (2010).

${ }^{14}$ V. Baltz and B. Dieny, J. Appl. Phys. 109, 066102 (2011).

${ }^{15}$ V. Baltz, Appl. Phys. Lett. 102, 062410 (2013).

${ }^{16}$ L. E. Fernandez-Outon, M. S. Araújo Filho, R. E. Araújo, J. D. Ardisson, and W. A. A. Macedo, J. Appl. Phys. 113, 17 D704 (2013)

${ }^{17}$ D. Kaya, P. N. Lapa, P. Jayathilaka, H. Kirby, C. W. Miller, and I. V. Roshchin, J. Appl. Phys. 113, 17D717 (2013).

${ }^{18}$ M.-A. Nicolet, Thin Solid Films 52, 415 (1978).
${ }^{19}$ S. Song, Y. Liu, M. Li, D. Mao, C. Chang, and H. Ling, Microelectron. Eng. 83, 423 (2006).

${ }^{20}$ M.-G. Sung, Y. S. Kim, S. J. Kim, I.-K. Jeong, H.-S. Choi, M.-S. Kim, H. Kim, and S.-K. Park, Solid-State Electron. 69, 22 (2012).

${ }^{21}$ S. Soeya, T. Imagawa, S. Mitsuoka, and S. Narishige, J. Appl. Phys. 76, 5356 (1994).

${ }^{22}$ E. Fulcomer and S. H. Charap, J. Appl. Phys. 43, 4190 (1972).

${ }^{23}$ P. Gibbs, T. M. Harden, and J. H. Smith, J. Phys. F: Met. Phys. 15, 213 (1985).

${ }^{24}$ R. K. Chouhan and A. Mookerjee, J. Magn. Magn. Mater. 323, 868 (2011).

${ }^{25}$ N. J. Gökemeijer, T. Ambrose, and C. L. Chien, Phys. Rev. Lett. 79, 4270 (1997).

${ }^{26}$ S. Bandiera, R. C. Sousa, B. Rodmacq, and B. Dieny, Appl. Phys. Lett. 100, 142410 (2012).

${ }^{27}$ V. Baltz, S. Auffret, and B. Dieny, IEEE Trans. Mag. 47, 3308 (2011).

${ }^{28}$ Y. J. Wang, Appl. Phys. A 68, 231 (1999).

${ }^{29}$ P. Bruno and C. Chappert, Phys. Rev. B 46, 261 (1992).

${ }^{30}$ J. Bass and W. P. Pratt, Jr., J. Phys.: Condens. Matter 19, 183201 (2007).

${ }^{31}$ Y.-J. Lee, C.-R. Changa, T.-M. Hong, C. H. Hoa, and M.-T. Lin, J. Magn. Magn. Mater. 240, 264 (2002).

${ }^{32}$ J. W. Cai, W. Y. Lai, J. Teng, F. Shen, Z. Zhang, and L. M. Mei, Phys. Rev. B 70, 214428 (2004).

${ }^{33}$ Y.-Y. Song, D.-H. Kim, S.-C. Yu, P. D. Kim, I. A. Turpanov, L. A. Lee, A. E. Buzmakov, and K. W. Lee, J. Appl. Phys. 103, 07C112 (2008).

${ }^{34}$ A. Paul, N. Paul, J. Jutimoosik, R. Yimnirun, S. Rujirawat, B. Höpfner, I. Lauermann, M. Lux-Steiner, S. Mattauch, and P. Böni, Phys. Rev. B 87, 014431 (2013).

${ }^{35}$ A. Tan, J. Li, C. A. Jenkins, E. Arenholz, A. Scholl, C. Hwang, and Z. Q. Qiu, Phys. Rev. B 86, 064406 (2012); Y. Meng, J. Li, P.-A. Glans, C. A. Jenkins, E. Arenholz, A. Tan, J. Gibbons, J. S. Park, C. Hwang, H. W. Zhao, and Z. Q. Qiu, ibid. 85, 014425 (2012). 